\title{
Sentence Comprehension and Working Memory in Malay Adults
}

\author{
Yazmin Ahmad Rusli ${ }^{a}$ \\ yazmin@ukm.edu.my \\ Faculty of Health Sciences, \\ Universiti Kebangsaan Malaysia \\ James Montgomery \\ montgoj1@ohio.edu \\ School of Rehabilitation and Communication Sciences, \\ Ohio University, United States
}

\begin{abstract}
Studies on sentence comprehension have centered on understanding the intersection between language and cognition. The aim of the current study was to examine the association between complex sentence comprehension and working memory (WM) in Malay adults. We predicted that WM storage (as indexed by performance on a WM listening span task) would be invoked during the processing of complex Malay sentences (object relatives), but not simple sentences (subject-verb-object). Sixty adults participated in the study; 30 Malay- and 30 English native speakers. The experimental tasks were developed in both Malay and English versions for both groups respectively. Participants completed (i) two sets of sentence comprehension tasks (whereby comprehension was determined via selection of the agent of the sentence), and (ii) a conventional WM listening span task. Tasks were designed to be structurally similar in terms of length (within the language) and meaning (across both languages). Both groups performed significantly better on the comprehension of simple sentences as compared to complex sentences and obtained similar mean scores on the WM listening span task. For Malay comprehenders, WM storage did not significantly correlate with comprehension of simple sentences as well as complex sentences. The same correlation pattern was also revealed for the English comprehenders. Our predictions were partially borne out. Findings suggest that participants' comprehension of complex sentences did not invite WM storage, as it would seem that both Malay and English participants were still able to comprehend these complex sentences without having to tax their WM capacity. Although we anticipated a relation, the absence of such an association is not entirely unexpected. Potential explanations are discussed in this article.
\end{abstract}

Keywords: Sentence Comprehension; Object Relatives; Working Memory; Listening Span; Malay

\section{INTRODUCTION}

The role of working memory (WM) in adult sentence comprehension has been widely explored for the English language. The one memory mechanism that has received the most attention is WM storage, with an eye toward determining whether comprehenders have sufficient memory storage to support comprehension. Complex sentence structures such as object relatives (OR) are often used as a means to examine the role of WM storage supporting sentence comprehension. In English, an association between WM storage and complex sentence comprehension has been observed repeatedly. However, research into the association between $\mathrm{WM}$ and complex sentence comprehension has received little attention across other languages.

a (Main \& Corresponding author) 
Examining this intersection in the Malay language would be an interesting cross language research pursuit because Malay, like English, is also primarily a subject-verb-object (SVO) word order language. The issue is whether the same association between WM storage and complex sentence comprehension as observed in English, is also observed in Malay. The purpose of the present study was to examine this intersection in the Malay language.

\section{MALAY: BACKGROUND AND BRIEF OVERVIEW OF THE LANGUAGE TOPOGRAPHY}

Malay is a member of the Austronesian family of languages, and that of the Western MalayoPolynesian subgrouping (Pereltsvaig, 2012). The Malay language, which is of interest in this study refers to the modern, standard variety which is primarily spoken in the South East Asia region. This standard is also known as Bahasa Indonesia (in Indonesia) and Bahasa Melayu (in Malaysia, Singapore, and Brunei). The data collected for this work was from the participation of native speakers of Bahasa Melayu in Malaysia. Despite the confines, which were primarily due to conveniences in sampling, it is noted that significant dialectal gaps in Malay would be expected when comparing colloquial varieties and the standard, rather than among the various standards listed above (Wee, 1996).

Malay shares many similar typological (syntactic) characteristics with English (Karim, Onn, Musa \& Mahmood, 1994; Razak, Jin, Lim \& Aziz, 2016). Both Malay and English are strict word order languages in which SVO is the predominate structure and most frequently used. As in English, relative clauses in Malay are sentential complements that are usually attached to one of the NPs in the main clause. Complex sentences with relative clauses in Malay are predominantly identified by the relative clause marker (or conjunction) yang that connects the two together (Karim et al, 1994; Hassan, 2002). However, unlike English, Malay is a prodrop language (Razak in Winskel and Padakannaya, 2014), and is often referred to as a nullsubject language.

Differences between the languages also become evident at the morphological and lexical levels. Malay is not a case-inflected language, (i.e., it has no markers on the noun phrase (NP) to tell the listener "who did what to whom") and does not make use of grammatical gender (i.e., the same word is used for he/she and him/her); instead, all pronouns are gender neutral, by which the speaker would have to add lelaki for "male" and perempuan for "female" to indicate gender for the child or adult. Malay also differs from English in the use of tense. Verbs are not marked for tense and instead it is denoted by time adverbs (e.g., esok for tomorrow) or the use of other tense indicators (e.g., telah for "has"; sedang for "is"; akan for "will" - that represents forms of past, present, and future tenses respectively). To indicate plurality, word reduplications are typically used (e.g., bantal-bantal "pillows" is the plural form for bantal "a pillow"). There are also instances of lexically determined reduplications that are used to denote variety. These are made by adding the suffix -an (e.g., buah-buahan "fruits or a spread of fruits" is the plural form for buah "a fruit"), or by making changes to some part of the duplicated word (e.g., calar-balar "multiple scratches" is the plural form for calar "a scratch") (Mohamed Salleh, Kawaguchi \& Di Biase, 2019). Speakers also use numeral classifiers (e.g., 3 buah rumah "3 houses" instead of rumah-rumah or "houses"), and while it can be omitted in Malay discourse (e.g., 3 rumah instead of 3 buah rumah), its use in written Malay discourse is necessary (Salehuddin, Winskel \& Maros, 2011; Salehuddin \& Winskel, 2012). There is also a complex system of verb affixes in rendering meaning and in denoting voice of intentional and accidental moods (Wee, 1996).

Despite Malay being one of the most widely used languages in the world and an influential trade language in South East Asia, it is surprising that it is the least studied language in the western world. Early descriptions of Malay and its grammar were formulated according 
to European-based descriptive categories even though Malay had been much more influenced by Sanskrit and Arabic at the time (Knowles \& Mohd Don, 2006). The strong assumption about how topographically similar Malay and English are, may be the reason why Malay has not been the subject of extensive linguistic research.

\section{LINGUISTIC DESCRIPTION OF OR SENTENCE COMPREHENSION}

Adults across many languages, including English, find complex OR structures difficult to understand (Booth, MacWhinney \& Harasakiet, 2000; Dick, Wulfeck, Krupa-Kwiatkowski \& Bates, 2004), Hebrew (Friedman, Belletti, \& Rizzi, 2009; Friedman \& Novogrodsky, 2004), Hungarian (Kas \& Lukas, 2012), and Italian (Adani, Van der Lely, Forgiarini \& Guasti, 2010; Arosio, Guasti \& Stucchi, 2011). Object relative structures have occupied a centerpiece in the adult sentence comprehension literature for a number of years because of their unique processing challenge due to their non-canonical nature. The difficulty with ORs, for example "The woman (NP1) that the man (NP2) had greeted walked into the courthouse"; from a syntactic perspective can be attributed to their greater complexity. In Malay and English, one index of complexity relates to word order, with ORs violating typical or canonical SVO word order (Abu Bakar, Razak \& Lim, 2016). In the example, NP1 (the woman) occupies the subject position but functions grammatically as the object and semantically as the patient, whereas the latter NP2 (the man) functions grammatically as the subject and semantically as the agent. It has been argued that comprehenders strive to recover the SVO structure of sentence constituents from non-canonical input (Chomsky, 1995; Hornstein \& Nunes, 2002; Kayne, 1994). To do so and to understand "who did what to whom", the comprehender must perform a movement operation whereby NP1 (the woman) 'moves' from its fronted object position to its canonical post-verb position (The man had greeted the woman).

Object relatives involve movement of NP1 from the object position to a non-argument position and movement across clausal boundaries. To recover an SVO representation and understand "who did what to whom", a syntactic movement operation is performed to establish what is called a filler-gap dependency, i.e., 'move' NP1 (filler) to a phonologically empty NP position, or trace (gap). To this end NP1 'moves' to its post-verb slot, i.e., syntactic gap $\left(\mathrm{t}_{\mathrm{i}}\right)$. To understand the OR sentence "The woman i that the man had greeted ti walked into the courthouse", NP1 (The woman) must be moved from its fronted object position to its rightful post-verb canonical position (the man had greeted the woman). The trace position is linked to the first NP through co-indexing $(i)$. It is at this point that NP1 is reactivated or retrieved from memory, and integrated into the developing syntactic (filler-gap) structure and verb argument structure such that the verb (greeted) can then assign a proper thematic role to each NP, i.e., agent to NP2 and patient to NP1. Research with adults reveals that comprehenders automatically reactivate NP1 (filler) from memory immediately upon encountering the gap. Importantly, it is NP1 that tends to be reactivated, not other NPs (i.e., NP2) appearing before the gap. Such NP reactivation has been demonstrated using a variety of paradigms, including, for example, cross modal priming (Hetstvik, Bradley \& Bradley, 2012; Swinney, Zurif, Prather \& Love, 1996) and event-related potentials (ERP) (Garnsey, Tanenhaus \& Chapman, 1989; Hetsvik, Maxfield, Schwartz \& Shafter, 2007; Kimball, 1973).

\section{ROLE OF MEMORY IN OR COMPREHENSION}

Memory has been posited to be an important determinant in complex sentence comprehension across the years (Gibson, 1998; Miller \& Isard, 1964). A variety of sentence complexity metrics have been proposed to help explain the nature of the memory load placed on comprehenders by complex grammatical structures. One such metric proposed was the number of intervening 
discourse referents (Lewis, 1996), which was based on the sentence processing theory of similarity-based interference. It is said that when to-be-remembered items (in this instance, NP1s) are followed by stimuli (or other NPs) that are similar along some dimensions (i.e., phonologically similar list of words, similar semantic category), the original items are more quickly forgotten, hence are unable to be recalled accurately. Interference effects are exhibited when items are stored in WM using similar codes in syntactic parsing. This source of difficulty has been found to be more evident for sentences with center embeddings (or nested dependencies), compared to right-branching embeddings even when it carries the same amount of embeddings, in either SVO or OR sentence types.

From a syntactic perspective, the challenge in processing OR sentences can be attributed to their complexity, whilst from a WM perspective, the difficulty lies in the greater memory demands that it imposes. Within the memory literature, several models of WM have been proposed (see Miyake \& Shah, 2007). Despite theory dependent differences in architectural and functional details, all models assume WM to be a multi-mechanism construct whose primary function is to allow individuals to store and maintain information in an active state while simultaneously performing some kind of mental activity (Baddley, 1999; Cowan, 1995; Engle, Tuholski, Laughlin \& Conway, 1999; Gordon, Hendrick \& Johnson, 2001, 2004). Working memory performance is conventionally measured using a complex span task that includes both a storage and processing component. In a listening span task, for example, comprehenders are presented sets of sentences and asked to (i) comprehend each sentence, (ii) remember a separate item such as a digit or word, and (iii) recall as many items in serial order as possible at the end of the set. Item recall is typically the primary dependent variable. A secondary variable is the score on the processing component, with individuals usually performing quite well.

In addition to some kind of limited-capacity storage, all models assume a resourcelimited attention mechanism (or central executive) comprising various control mechanisms. It has been argued that these control mechanisms play a critical role in WM performance (Cowan, 1995; Cowan et al, 2005; Gordon et al, 2001, 2004). One such control mechanism is attention focus switching (Gordon et al, 2001; Kane, Bleckley, Conway \& Engle, 2001). During WM performance, it is argued that an individual must rapidly switch his/her attentional focus between the processing and storage components. In doing so, he/she allocates attentional focus to the processing activity immediately followed by a momentary switch of attention away from processing to storage in order to refresh the to-be-recalled items. These rapid switches of attention facilitate overall WM performance by allowing an individual to perform the mental activity with good success and keep the storage items active and accessible for later retrieval.

An overwhelming majority of research examining the influence of WM on complex sentence comprehension has focused on the role of memory storage (Just \& Carpenter, 1992; Lewis, 1996; Robert, Marinis, Felser \& Clahsen, 2007; Unsworth \& Engle, 2008). This intersection has been studied using various methods, including, for example, an individual differences approach and dual-task experiments. In individual differences studies, the sentence processing/comprehension of low WM and higher WM individuals are compared. The assumption is that, relative to high WM individuals, low WM individuals would perform more poorly on complex sentences but not simple sentences. Experimental evidence indeed suggests that low WM individuals, relative to those with higher WM, show significantly greater difficulty processing and comprehending complex structures (Hestvik, Bradley \& Bradley, 2007; Just \& Carpenter, 1992; Just, Carpenter \& Keller, 1996; Roberts et al, 2007). In dualtask experiments, comprehenders are presented with external memory loads at various points during the processing of simple and complex sentences. The assumption is that imposing an external memory load during complex sentence processing should lead to a systematical decrease in comprehension accuracy and slow judgment speed. Experimental evidence 
supports these assumption (Belletti, Friedmann, Brunato \& Rizzi, 2012; Leech, Aydelott, Symons, Carnevale \& Dick, 2007; McElree, Foraker \& Dyer, 2003; Von Berger, Wulfeck, Bates \& Fink, 1996).

\section{CROSS LINGUISTIC RESEARCH ON WM AND SENTENCE COMPREHENSION}

Most cross linguistic studies have focused on describing similarities and differences in linguistic properties across different languages, often with English as a reference language. In these studies, typically, languages with very different grammatical and extra-grammatical structures to English are of interest, based on elements such as word order, animacy, stress, contrastive stress, case inflections, topicalization, and semantic versus syntactic strategies used by native speakers in processing sentences (Bates, McNew, MacWhinney, Devescovi \& Smith, 1982). It is only more recently that cross linguistic studies have taken a turn to investigate the role of WM in processing complex sentences, with the goal of understanding whether similar cognitive mechanisms are used during language comprehension across languages that differ in topography, i.e., comparing English with German (Vos \& Friederichi, 2003) or Dutch (Swets, Desmet, Hambrick \& Ferreira, 2007) or Korean (Kim \& Christianson, 2012). These studies have found that individuals' WM capacity is a major determinant on how individuals perform their syntactic parsing and the kinds of strategies that they are able to employ when faced with different forms of sentence comprehension tasks. However, this literature is very small.

In general, extant cross-language studies show that language dependent-accounts of cross linguistic differences in the processing of complex sentences have often passed over the interaction between individuals' WM capacity and a language's general structure. Such a lack of cross-language research examining the intersection of cognition and language comprehension has motivated the present study. The present study aims to examine to what extent WM storage is involved when looking at Malay and English sentence comprehension. The issue is whether memory storage will be invoked during complex sentence comprehension in Malay, as it has been shown for English. Results of the present study will be important because they will contribute to the emerging cross-language literature that has begun to focus on the intersection of cognition and language comprehension.

Notwithstanding the differences between both languages in some respect (i.e., the use of morphology), it is the similarities between them (i.e., word order language, syntax structures) that allows us to understand the WM-comprehension relationship better. This is especially true since both SVO and OR sentences could be matched in length in Malay, which typically is confounded for English. Studying the association between WM and comprehension in Malay allows us to ascertain that in the comprehension of OR sentences, we can truly test the hypothesis that it is "movement of NP1" and not any "inconsequential" differences in the length of ORs that implicates WM storage in sentence processing.

\section{RESEARCH QUESTION AND OBJECTIVES}

The aim of the present study was to investigate whether the comprehension of Malay complex sentences imposes similar WM storage and processing demands for Malay comprehenders, as the comprehension of English complex sentences does for English comprehenders; as indexed by performance on a conventional WM listening span measure. Two types of sentences in both languages were used to address this question; simple SVO sentences (e.g., The little cat hugged the big dog) and complex OR sentences (e.g., The big dog that the little cat hugged was happy) in which there is a violation of typical or canonical SVO word order. The predictive outcomes of the study were as follows: 
i. For simple SVO sentences, no significant correlation between WM and sentence comprehension was expected to be obtained for either English or Malay comprehenders,

ii. For complex OR sentences, a significant positive correlation between WM and sentence comprehension was expected to be obtained for both English and Malay comprehenders.

Both these predictions were based on evidence from previous adult studies that have found significant correlations between performance on conventional listening span tasks and complex sentence comprehension (Just \& Carpenter, 1992; King \& Just, 1991). With both Malay and English having similar word order language features (in indexing sentence complexity), it is anticipated that comprehenders from both groups would be utilizing the obligatory syntactic movement operation that is required when processing complex sentences, which in turn would lead to noticeable recruitment of WM storage capacities.

\section{METHOD}

\section{PARTICIPANTS AND TESTING LOCATIONS}

A total of 60 adults participated in the study, with ages that ranged from 21 to 38 years. Participants comprised 30 native Malay and 30 native English speakers. Participants completed a brief intake form related to medical history and educational status. None of the participants reported a history of, or current neurological, psychological and emotional impairment(s). Likewise, none of them reported any language problems or learning disability. Table 1 displays the educational status of the participants.

TABLE 1. Educational status of participants

\begin{tabular}{lllllllll}
\hline Group & $\begin{array}{l}\text { Age } \\
\text { M }(\boldsymbol{S D})\end{array}$ & Gender (Percentage) & \multicolumn{2}{l}{ Education level (Percentage) } \\
\cline { 3 - 9 } & & Male & Female & $\begin{array}{l}\text { High } \\
\text { school }\end{array}$ & $\begin{array}{l}\text { Some } \\
\text { college }\end{array}$ & $\begin{array}{l}\text { 2-year } \\
\text { college }\end{array}$ & $\begin{array}{l}\text { 4-year } \\
\text { college }\end{array}$ & $\begin{array}{l}\text { Advance } \\
\text { degree(s) }\end{array}$ \\
\hline Malay & $29.70(4.97)$ & 50.00 & 50.00 & 23.30 & 0.00 & 10.00 & 36.70 & 30.00 \\
English & $23.77(3.99)$ & 16.70 & 83.30 & 13.30 & 33.30 & 6.70 & 26.70 & 20.00 \\
\hline
\end{tabular}

Participants also completed a brief form focusing on their native language status. They self-rated their native and any second language proficiency and frequency of language use on a 5-point Likert-scale, including speaking, reading, and writing (Proficiency: $1=$ no ability at all; $5=$ native-like ability) (Frequency: $1=$ never/almost never used; $5=$ main language used) (Taube-Schiff \& Segalowitz, 2005). All of the Malay participants rated Malay as their native language and all English participants rated English as their native language. For both groups, participants rated the proficiency in their native to be significantly higher than any second language that they might have spoken (results from separate within-subjects repeated measures ANOVA for Malay ratings: $F(1,29)=61.919, \mathrm{p}<0.001$; and for English ratings: $F(1,29)=$ $708.330, \mathrm{p}<0.001)$. Similar findings were obtained for the frequency of language use, with native languages being used more significantly than any second language that they might have used (Malay ratings: $F(1,29)=29.649, p<0.001$; and English ratings: $F(1,29)=2237.057$, $\mathrm{p}<0.001)$. Table 2 displays the mean rating of participants' language proficiencies and frequencies of the languages used.

All participants had normal hearing sensitivity for the frequencies $500 \mathrm{~Hz}, 1 \mathrm{kHz}, 2 \mathrm{kHz}$, and $4 \mathrm{kHz}$ as determined by screening, at $25 \mathrm{dBHL}$ for those screened at Ohio University (OU), and at $35 \mathrm{dBHL}$ for those screened at Universiti Kebangsaan Malaysia (UKM). Differences in cut-off thresholds were primarily attributed to the differences in ambiance noise between the two testing sites. Despite the difference, it is important to note that experimental testing was conducted under the use of headphones. 
Participants were recruited by means of purposive and convenient sampling through the promotion of the project by the primary investigator (PI) in OU and UKM. Participation was on a voluntary basis, and souvenirs were presented to all participants as a token of appreciation. Two testing locations have been utilized; namely the Developmental Psycholinguistics Lab in Grover Center, OU and the Audiology and Speech Sciences Clinic in UKM Kuala Lumpur campus, Malaysia. Separate ethical approvals were obtained from both locations prior to commencing with the testing sessions.

TABLE 2. Mean rating of participants' language proficiencies and frequencies of the languages used within the respective modalities

\begin{tabular}{|c|c|c|c|c|c|c|c|}
\hline & & \multicolumn{3}{|c|}{ Language proficiency } & \multicolumn{3}{|c|}{ Frequency of use } \\
\hline & & Speaking & Reading & Writing & Speaking & Reading & Writing \\
\hline \multirow[t]{2}{*}{ L1: Malay } & $M$ & 4.83 & 4.90 & 4.66 & 4.83 & 4.56 & 4.43 \\
\hline & $S D$ & 0.37 & 0.30 & 0.54 & 0.37 & 0.85 & 0.89 \\
\hline $\mathrm{L} 2$ & $M$ & 3.51 & 3.75 & 3.56 & 3.25 & 3.62 & 3.29 \\
\hline $\begin{array}{l}\text { (For Malay } \\
\text { speakers) }\end{array}$ & $S D$ & 0.72 & 0.73 & 0.65 & 0.83 & 0.94 & 0.94 \\
\hline \multirow[t]{2}{*}{ L1: English } & $M$ & 5.00 & 5.00 & 5.00 & 5.00 & 5.00 & 5.00 \\
\hline & $S D$ & 0.00 & 0.00 & 0.00 & 0.00 & 0.00 & 0.00 \\
\hline L2 & $M$ & 2.90 & 2.30 & 2.10 & 1.80 & 1.30 & 1.20 \\
\hline $\begin{array}{l}\text { (For English } \\
\text { speakers) }\end{array}$ & $S D$ & 0.65 & 0.57 & 0.65 & 0.27 & 0.44 & 0.27 \\
\hline
\end{tabular}

*L2 may comprise one or more of the participants' second language(s)

\section{EXPERIMENTAL TASKS}

\section{STIMULUS RECORDING PROCEDURES}

All stimuli were recorded in a sound-treated booth, using the WinBliss7 software (Mertus, 2000), and subsequently edited using the Adobe Audition version 2. It was normalized for intensity using the WinBliss7 software. For the sentence comprehension task, two different adult female speakers read the Malay and English sentences, while for the WM task, two different adult male speakers read the Malay and English sentences. Sentences were read with a normal rate, using normal prosodic variation. Both Malay speakers had no distinctive dialects; likewise, both English speakers had Midwest American English dialect.

\section{SENTENCE COMPREHENSION TASK}

\section{TASK DESIGN AND STIMULI}

The sentence comprehension task was developed as the outcome measure for the study. The task was intended to measure adults' comprehension of SVO and OR sentences via the selection of the agent of the sentence. The selection of the accurate target demonstrated an understanding of the notion, "who did what to whom", with the comprehender correctly identifying the subject and object (agent, patient) of the sentence. A total of 90 sentences were created for each of the Malay and English task versions. Each version comprised $45 \mathrm{SVO}$ and 45 OR sentences. Sentences across the versions were controlled in a variety of ways, including the selection of vocabulary (with reference to the NPs, VPs and embedded relative clauses) and tense. Sentences were also controlled for length. Both Malay and English SVO sentences matched in the total number of morphemes (nine morphemes across all sentences). However, Malay OR sentences were found to be significantly shorter than English OR sentences, $t_{(44)}=$ 
$-26.0 ; \mathrm{p}<0.001$. This difference was attributed to the fact that for Malay, both SVO and OR sentence lengths were able to be matched (nine morphemes across all sentences). However, for English, due to its linguistic properties, SVO and OR sentences were not able to be matched in length, with ORs being relatively longer compared to SVOs (10-11 morphemes for ORs as compared to nine morphemes for SVOs).

Across all sentences, nine animal names were used to represent both agent (NP1) and patient (NP2) roles. All NPs were controlled for syllable length: two for Malay (except for bear - beruang, which has three syllables) and one for English. Importantly, all of the animals were common to both cultures ensuring geographical and cultural suitability and representativeness. Each animal noun was used as NP1 in half of the sentences and as NP2 in the remaining half. Fifteen verbs were selected and were used across sentences. For SVOs, verbs selected were constrained to Malay active voice verbs that could be paired with the prefix meN- to indicate that the action is violational (Hassan, 2002). This manipulation was necessary to keep the number of morphemes in the VP to a maximum of three across Malay sentences (1). Finally, we also ensured for the ORs that the same verbs (as in the SVOs) will be able to be used in its root form.

SVO

Malay: $\quad$ Anjing besar itu telah mencium kucing kecil itu

Gloss translation: Dog big the has meN-kiss cat little the (No. of morphemes: 9)

$\begin{array}{ll}\text { English: } & \text { The big dog has kissed the little cat } \quad \text { (No. of morphemes: 9) }\end{array}$

OR

Malay: $\quad$ Kucing kecil yang anjing besar itu cium sedang tidur

Gloss translation: Cat small that dog big the kiss is sleep (No. of morphemes: 9)

English: $\quad$ The small cat the big dog kissed is sleeping $\quad$ (No. of morphemes: 11)

All of the sentences were also semantically reversible. Each animal noun appeared as NP1 in half of the sentences and as NP2 in the other half. The verbs selected were neutral regarding which animal could perform the action on the other. Thus, each animal had comparable probability of performing the action on the other, thereby minimizing any systematic bias on the part of the comprehender to interpret one NP over another as the agent. This design feature also permitted maximal flexibility in using each animal name in both NP positions.

For both sentence types, three high-quality color illustrations from Rossion and Pourtois (2004) were used to depict the choice of target responses; two matching the sentence nouns and one foil. Across the 90 sentences within both tasks sets, the location of the target picture appeared almost equally on the left, center and right side of the screen.

\section{PROCEDURE}

The task included a total of $90 \mathrm{SVO}$ and OR sentences, randomly divided into two task sets. Within each set, no more than two consecutive presentations of any one sentence type were designed to occur. Participants sat in front of the touch screen monitor with their fingers of their dominant hand placed on a red dot located on the bottom part of a touch screen frame. The participants listened to a sentence about an animal doing something to another animal, and then immediately at sentence offset, three images were displayed; one corresponding to the 
agent of the sentence, one to the patient (recipient of the action), and one foil. He/she was asked to touch the picture of "the animal that is doing action onto the other animal" to indicate the agent in the sentence as quickly as possible. The PC-internal clock would start at picture onset and stop as soon as the participant touched a picture. The researcher controlled the pace of the task. Figure 1 depicts the flow of a trial within the sentence comprehension task.

\section{DEPENDENT VARIABLE}

The dependent variable was the percentage of sentences comprehended accurately (total number of correct agent selection).

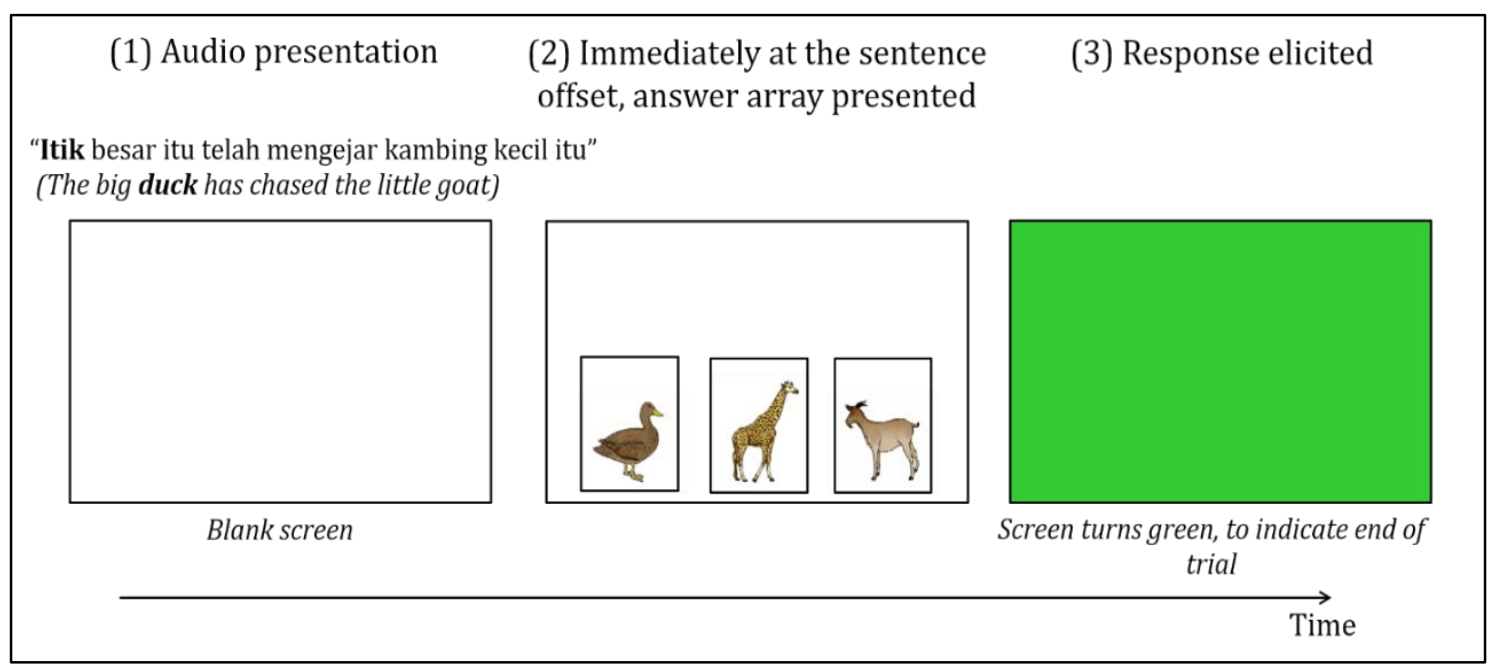

FIGURE 1. Example of a trial from the sentence comprehension task

\section{WORKING MEMORY TASK}

TASK DESIGN AND STIMULI

The WM task used was a conventional WM listening span task in which comprehenders were asked to listen to sets of sentences and (i) comprehend the truth value of each sentence, (ii) remember a digit presented after each sentence, and (iii) recall all the post-sentence digits in serial order following the last sentence in the set. The task comprised both Malay and English versions. In this study, the English version was adapted from Nagaraj (2014); whereas for the Malay version, the quality of translated items was evaluated by a linguist who specializes in Malay morphology and syntax to ensure that the sentences matched the English version as close as possible in terms of meaning.

This computer-based task included sets of sentences that varied from 3 to 7 sentences, with each set comprising three trials. The task included approximately equal numbers of SVO and OR sentences, which totaled to 75 sentences. Approximately half the sentences required a "Yes" response (sentence had truth value) while the remaining half required a "No" response (sentence had no truth value). To ensure the participants would process the false items in their entirety prior to making a truth value judgment, the semantic violation would occur in different locations, i.e., NP1 and NP2 (2). All of the English sentences ranged from 11 to 14 morphemes, while the Malay sentence ranged from 10 to 16 morphemes. Paired t-test analysis revealed that the overall Malay sentences were significantly longer as compared to English sentences; $t$ (74) $=-5.433 ; \mathrm{p}<0.001$. 
i.e., SVO (True version: No semantic violation)

$$
\begin{aligned}
\text { Malay: } & \text { Kucing itu telah memanjat pokok di padang sebelah bangsal itu } \\
\text { Gloss translation: } & \text { Cat the has meN-climb tree at field next to barn the } \\
\text { English: } & \text { The cat climbed the tree in the field by the barn } \\
& *_{c} \text { cat - climb - tree } \rightarrow \text { which made the sentence semantically plausible }
\end{aligned}
$$

i.e., OR (False version: Semantic violation present)

$$
\begin{aligned}
\text { Malay: } & \text { Lelaki yang peta itu teliti di pantai itu sangat mengelirukan } \\
\text { Gloss translation: } & \text { Man that map the study at beach the very meN-confuse-kan } \\
\text { English: } & \text { The man that the map studied at the beach was confusing } \\
& \text { *map - studied - man } \rightarrow \text { which made the sentence semantically implausible }
\end{aligned}
$$

\section{PROCEDURE}

As in the Sentence Comprehension task, participants sat in front of the touch screen monitor with their fingers of their dominant hand placed on a red dot located on the bottom part of a touch screen frame. The layout of the screen was such that the sign "+" separated the word "Ya" (left of "+") and "Tidak" (right of "+") for the Malay version, and "Yes" (left of "+") and "No" (right of "+") for the English version. They were told that they would hear a man saying some groups of sentences and that they will do three things: (i) listen to each sentence and respond to the truth value of each by touching "Yes" or "No"; (ii) remember a digit presented after each sentence; and (iii) at the end of the sentence set list or trial, recall as many digits as possible in the order they were presented.

Participants were asked to respond as quickly as possible without compromising their accuracy in their comprehension judgment, and immediately following their response, listen to the digit presented. Regardless of any differences across the participants in the time they take to comprehend the sentence, the immediate presentation of each new digit and new sentence following (within the trial) would prevent them from rehearsing the digits between sentence items. Following the presentation of an entire set of sentences or a trial, the monitor would turn green, cueing participants to recall the digits in serial order.

The comprehension response accuracy was automatically recorded by the E-Prime version 1 (Schneider, Eschman, \& Zuccolotto, 2002), whereas digit recall was recorded manually by the examiner on the score sheets.

\section{DEPENDENT VARIABLE}

The primary dependent variable was the accuracy of serial digit recall (which relates to the storage component of WM). Accuracy score was calculated using a partial-credit unit scoring scheme on a trial by trial basis (Conway et al, 2005). In the serial digit recall scheme, one point was given for a correct response for each of the item within the trial. For items that contained errors, partial-credit was given by dividing the number of correct digit(s) recalled over the total number of digits for the item within the trial.

\section{GENERAL TESTING PROCEDURES}

Participants were scheduled to be seen individually in one session which lasted for approximately 30 to 40 minutes, inclusive of screening procedures, experimental testing, and rest breaks. All testing was conducted using a MacBook Pro laptop connected to a 17" Elo 
touch screen. Stimuli were delivered, and participant responses were documented via the EPrime Version 1. Three counterbalanced orders of the experimental tasks were created, and equal numbers of adults received one of the counterbalanced orders ( $n=20$ for each order). Participants sat in front of a computer monitor and each task was presented under headphones at a comfortable listening level as determined by the participant.

\section{RESULTS}

\section{RELIABILITY OF THE WORKING MEMORY AND SENTENCE COMPREHENSION TASKS}

Cronbach alpha analysis were run separately for both Malay and English versions of the WM task $(\mathrm{n}$ items $=75)$ and sentence comprehension task $(\mathrm{n}$ items $=90)$ to determine the reliability coefficient of the tasks. Reliability values obtained for the Malay and English versions of the WM tasks were 0.942 and 0.934, respectively. Reliability for the Malay and English versions of the sentence comprehension tasks were 0.948 and 0.945 , respectively. Table 3 displays the summary of the reliability analysis.

TABLE 3. Cronbach Alpha results for Malay and English versions of the working memory and sentence comprehension tasks

\begin{tabular}{lllll}
\hline & \multicolumn{2}{l}{ Working Memory Task } & \multicolumn{2}{l}{ Sentence Comprehension Task } \\
\cline { 2 - 5 } & Malay version & English version & Malay version & English version \\
\hline Cronbach's Alpha & 0.942 & 0.934 & 0.948 & 0.945 \\
Cronbach's Alpha & 0.941 & 0.933 & 0.933 & 0.937 \\
based on standardized items & & & & \\
N of item (included) & 69 & 67 & 66 & 66 \\
$M$ & 48.433 & 46.030 & 55.766 & 59.270 \\
Variance & 173.289 & 144.930 & 127.220 & 86.616 \\
$S D$ & 13.163 & 12.039 & 11.279 & 9.307 \\
\hline
\end{tabular}

\section{PRELIMINARY ANALYSIS}

For both the WM and sentence comprehension tasks, the data were examined for distributional normality. For the WM task, the Malay data were found to be non-normally distributed (Shapiro-Wilk, $\mathrm{p}=0.002$ ). The English WM task data, however, were normally distributed (Shapiro-Wilk, $\mathrm{p}=0.082$ ). For the sentence comprehension task, both the Malay and English data were found to be non-normally distributed (Shapiro-Wilk, $p=0.001$ ).

All non-normally distributed data were transformed (using logarithm and inverse square root) to handle violations of normality (Tabachnick \& Fidell in Meyers, Gamst \& Guarino, 2013). However, even after transformation the distribution remained non-normal. Because both data sets have relatively small sample sizes $(n=30)$, the violation of normality assumption would not permit the use of parametric procedures. Hence, non-parametric statistical tests were subsequently used to analyze both data sets.

\section{PARTICIPANTS' PERFORMANCE ON THE WORKING MEMORY AND SENTENCE COMPREHENSION TASKS}

\section{WORKING MEMORY}

The partial-credit unit scoring scheme (Conway et al., 2005) that was used to calculate participants' accuracy of serial digit recall scores on a trial by trial basis, allowed participants to obtain a maximum score of one per trial. For Malay participants, the mean score obtained 
was 0.77. English participants scored similarly, obtaining a mean score of 0.76. Table 5a displays the descriptive summary of the accuracy of serial digit recall scores for both groups.

TABLE 5a. Descriptive summary of the accuracy of serial digit recall scores for Malay and English participants

\begin{tabular}{llll}
\hline & \multicolumn{4}{l}{ Accuracy of serial digit recall scores } \\
\cline { 2 - 4 } & $\boldsymbol{M}$ & $\boldsymbol{S D}$ & Range \\
\hline Malay participants & 0.77 & 0.15 & $0.34-1.00$ \\
English participants & 0.76 & 0.14 & $0.42-1.00$ \\
\hline
\end{tabular}

\section{SENTENCE COMPREHENSION}

For Malay participants, the mean comprehension accuracy score for SVO sentences was $98 \%$ and $79 \%$ for the OR sentences. This difference was significant (Wilcoxon signed rank test, $\mathrm{z}=$ -4.359, $\mathrm{p}<0.001)$. For English participants, a similar pattern emerged. The mean comprehension accuracy score for SVO sentences was $98 \%$ and for OR sentences $86 \%$. This difference, too, was significant (Wilcoxon signed-rank test, $\mathrm{z}=-3.981, \mathrm{p}<0.001$ ). Table $5 \mathrm{~b}$ displays the descriptive summary of the sentence comprehension accuracy scores for Malay and English participants.

TABLE 5b. Descriptive summary of the sentence comprehension accuracy scores for Malay and English participants

\begin{tabular}{llll}
\hline & & \multicolumn{2}{l}{ Sentence comprehension accuracy scores } \\
\cline { 3 - 4 } & & SVO & OR \\
\hline Malay participants & $M$ & 97.92 & 79.18 \\
& $S D$ & 3.59 & 25.13 \\
& Range & $86.67-100.00$ & $8.89-100.00$ \\
\hline English participants & $M$ & 98.07 & 86.94 \\
& $S D$ & 4.51 & 18.53 \\
& Range & $77.78-100.00$ & $42.22-100.00$ \\
\hline
\end{tabular}

\section{CORRELATION BETWEEN WORKING MEMORY AND SENTENCE COMPREHENSION}

A Spearman correlation was computed between the participants' WM score (serial digit recall) and accuracy score for SVO sentence comprehension and OR sentence comprehension to determine the association between WM storage and sentence comprehension. This analysis was computed for both Malay and English participants. For Malay participants, results indicated no relation between WM and comprehension of either OR sentences $(\mathrm{r}=0.330, \mathrm{p}=$ $0.075)$ or SVO sentences $(r=0.322, p=0.082)$. Similarly, for English participants, no relation was found between WM and comprehension of OR sentences $(r=0.271, p=0.147)$ or SVO sentences $(r=0.328, p=0.077)$.

\section{DISCUSSION}

The aim of the present study was to examine whether WM storage, as indexed by performance on a conventional WM listening span measure, would be invoked during the processing of complex Malay sentences but not simple sentences. This prediction was based on findings from English sentence comprehension, which has often shown this pattern. Our predictions were partially borne out. For Malay comprehenders, WM storage did not significantly correlate with complex sentence comprehension. Consistent with our predictions, WM storage did not correlate with simple sentence comprehension. The same correlation pattern was also revealed for the English comprehenders. Findings suggest that participants' comprehension of complex sentences did not invite WM storage. Possible reasons for these findings and potential other 
explanations for the sentence comprehension pattern exhibited by both the Malay and English comprehenders are discussed below.

\section{SUMMARY ON PARTICIPANTS' PERFORMANCE ON THE EXPERIMENTAL TASKS}

\section{WORKING MEMORY}

Participants' performance on the WM task was consistent with previous studies on adults (i.e., Riffle \& DiGiovanni, 2014; Nagaraj, 2014). Participants showed poorer serial recall of digits as sentence sets became longer. The serial recall scores across participants in both the Malay and English groups were similar, with the Malay group showing a mean score of $77.0 \%$ correct and the English group showing a mean score of $76.0 \%$.

\section{SENTENCE COMPREHENSION}

Both Malay and English participants demonstrated very strong comprehension of the SVO sentences, as demonstrated by their attaining a mean accuracy score of $97.92 \%$ for Malay and 98.07\% for English. These findings are consistent with the adult literature showing that comprehenders have little difficulty in understanding SVO structures because of their canonical nature. Comprehenders understand NP1, which occupies the subject position, to function as agent (i.e., Fedorenko, Gibson \& Rohde, 2006). Both the Malay and English comprehenders also showed good comprehension of the complex OR sentences, with the Malay group obtaining a mean score of $79.18 \%$ and the English group attaining a mean score of $86.94 \%$.

Although the participants performed well in each sentence type it is also true that they showed poorer comprehension of the OR sentences than the SVO sentences. This pattern was true for both groups and the findings are consistent with the adult sentence comprehension literature (i.e., Gordon et al, 2001, 2004). This consistent pattern is even more interesting considering that the OR sentences used in the present study were quite short, with approximately 10 to 11 morphemes across English sentences (i.e., about nine words per sentence).

From a linguistic perspective, relative to SVO comprehension, the poorer comprehension of OR sentences can be attributed to the fact that NP1 must be moved to the position behind the embedded VP and then assigned the patient role by the VP (e.g., Hetsvik et al, 2012). No such movement is required of SVO structures thereby making them easier to comprehend than OR structures. From a memory-based perspective, OR sentences are more difficult to comprehend than SVO sentences because of the presumed memory requirements of the sentences (Robert et al, 2007). Comprehenders must be able to hold NP1 in WM until encountering the embedded VP. It is at this point NP1 must then be reactivated from WM. The embedded VP provides the cue for NP1 to be reactivated at this point thereby allowing the comprehender to recover the SVO structure of the sentence. The potential role of WM storage is further discussed.

\section{EXPLAINING THE RELATIONSHIP BETWEEN WM STORAGE AND SENTENCE COMPREHENSION}

As predicted, WM did not correlate with SVO comprehension for either the Malay or English comprehenders. Conversely, it was anticipated that there would be a relation between WM storage and OR sentence comprehension, for both groups. However, no evidence of such a relation was found. Although we anticipated a relation, the absence of such an association is 
not entirely unexpected, whereby more studies have reported a minimal role of WM storage in complex sentence comprehension. The argument is that for most complex sentences there is no need for comprehenders to maintain more than two or perhaps three unintegrated NPs (i.e., Gordon, Hendrick \& Levine, 2002), a memory load that should be well within most comprehenders capacity. Instead, some authors (e.g., Andrews, Birney \& Halford, 2006) have argued that other memory-related variables such as the central executive and attention may play a more central role than storage in comprehension. Andrews et al (2006) investigated the nature of the cognitive demands imposed on OR sentences and found that processing relied more heavily on a domain-general capacity to process complex relations than on WM capacity. In their study, the authors contrasted a relational complexity stance (which they opted for) against a WM capacity stance, to investigate which account better explained individual differences in complex sentence comprehension. Relational complexity and WM approaches differ in their assumption about the precise nature of the load imposed when processing complex sentences. Unlike WM approaches, which focuses on the exclusive role of storage in comprehension (and is indexed by tasks that captures storage capacity as the dependent variable), relational complexity focuses on processing load and the number of interacting relations to be processed, which can be applied in any cognitive task (see Halford, Wilson \& Phillips (2006) for more on the metrics used to index relational complexity).

Another possible memory-related factor contributing to complex sentence comprehension relates to similarity-based retrieval interference effects (Gordon et al., 2002; Gordon et al., 2006; Lewis, Vasishth \& Van Dyke, 2006; Van Dyke, 2007; Van Dyke \& Lewis, 2003; Van Dyke \& McElree, 2006, 2011). Rapid item retrieval is the result of a direct access mechanism which enables an item in memory to be immediately retrieved during sentence processing based on the cues available at retrieval (McElree, 2000). However, rapid item retrieval (i.e., NP1 reactivation) is strongly influenced by similarity-based retrieval interference (Gordon et al., 2002; Gordon et al., 2006; Lewis et al., 2006; Van Dyke, 2007; Van Dyke \& Lewis, 2003; Van Dyke \& McElree, 2006, 2011). If the cues available at retrieval are not sufficiently distinctive to elicit reactivation of the target item over competing (syntactically and/or semantically similar) items also present in memory, then retrieval interference arises. Under these conditions, an inappropriate item may be retrieved (i.e., NP2) and comprehension compromised. However, when adequate cues are available similarity-based retrieval interference is reduced or even eliminated (Van Dyke \& McElree, 2011).

That both the Malay and English comprehenders in the present study showed significantly poorer OR comprehension than SVO comprehension appears to be consistent with this possibility, especially given the nature of the present sentences. Recall that the sentences were constructed with the intent to reduce the probability of one NP being favored over the other to be interpreted as the agent of the sentence. This manipulation thus likely increased the competition between NP1 and NP2, with comprehenders being less certain about which NP to reactivate at the gap. In other words, the lack of clear retrieval cues at the gap gave rise to similarity-based interference between NP1 and NP2.

A final potential explanation for the absence of correlation between WM storage and OR sentence comprehension relates to the nature of the sentences used in the present study. The construction of the sentence comprehension task stimuli was approached from a 'minimalist' stance (see Carpenter, Miyake \& Just, 1994). In order to make sure that both Malay and English sentences were the same length, and with the constraints posed when selecting the verbal affixes to match the tense and control the number of morphemes for sentences in both language versions, we opted for parsimony. It was essential to ensure that the performance of the Malay group could be mapped onto the performance of the English group, in order to allow interpretations on whether similar association between WM storage and complex sentence comprehension was to be observed in both groups. There were notable differences in sentence 
length between the English sentences developed for the present study, which was relatively short ( $\sim 9$ words for ORs), as compared to those used in previous sentence comprehension studies, e.g., Booth et al (2000) ( 12 words for SOs; subject-object relative clause). Therefore, despite the complexities posed in processing the Malay and English ORs, another possible reason for the lack of correlation between WM storage and OR sentences could be attributed to the degree to which WM storage was elicited through the sentence comprehension task. It would seem that both Malay and English participants were still able to comprehend these OR sentences without having to tax their WM capacity.

\section{CONCLUSION AND FUTURE DIRECTIONS}

Working memory load imposed by comprehension has been known to be directly related to sentence complexity. The sources of complexity within the sentences designed in the present study were based on the noncanonical word order of the complex OR sentences, which required comprehenders to retain NP1 while computing other roles within the sentence. Since working memory storage was not implicated in the processing of these sentences, findings from the present study may be used as a baseline on the sources of complexity that could be included/manipulated, to ascertain the potential relationship between WM capacity and the comprehension of Malay OR sentences (e.g., varying the number of thematic roles associated with the target verb, manipulating the number of verbs and nouns within the sentence, and the nouns' thematic roles in different clauses) (Carpenter et al., 1994). For the next steps, this would allow us to further gauge the starting points to when the comprehension of complex sentences begins to recruit and tax WM storage.

At the task level within the present study, Malay has shown to have similar sentence processing mechanisms to English and does seem to be a good language to use to study the implications of WM in comprehension, since both its simple and complex sentences could be matched in length. This ascertains the hypothesis that it is the "movement of NP1" and not a result of any "inconsequential" differences in the length of OR sentences, that is important in understanding the WM-comprehension relationship. It would also be interesting to investigate at which juncture the similarities in both languages would begin to depart from one another (if any) and where the linguistic differences between the Malay and English language would come into play. Future studies could also delve into the contribution of WM capacity by examining a wider range of complex sentences and sentence lengths. Other memory-related mechanism such as the executive or attentional control could also be investigated. With directions leaning toward examining online sentence comprehension, it would also be interesting to study comprehenders' processing strategies and determine whether any differences would be displayed when studying this intersection between languages.

\section{REFERENCES}

Abu Bakar, N., Razak, R. A. \& Lim, H. W. (2016). Pemerolehan klausa relative dalam kalangan kanak-kanak Melayu: Satu kajian awal. GEMA Online ${ }^{\circledR}$ Journal of Language Studies. 16, 145-165.

Adani, F., Van der Lely, H. K. J., Forgiarini, M. \& Guasti, M. T. (2010). Grammatical feature dissimilarities make relative clauses easier: A comprehension study with Italian children. Lingua. 120, 2148-66.

Andrews, G., Birney, D. \& Halford, G. (2006). Relational processing and working memory capacity in comprehension of relative clause sentences. Memory \& Cognition. 34, 13251340. 
Arosio, F., Guasti, M. \& Stucchi, N. (2011). Disambiguating information and memory resources in children's processing of Italian relative clauses. Journal of Psycholinguistic Research. 40, 137-154.

Baddeley, A. (1999). Human memory: Theory and practice. Hove, UK: Psychology Press.

Bates, E., McNew, S., MacWhinney, B., Devescovi, A. \& Smith, S. (1982). Functional constraints on sentence processing: A cross-linguistic study. Cognition. 11, 245-299.

Belletti, A., Friedmann N., Brunato D. \& Rizzi L. (2012). Does gender make a difference? Comparing the effect of gender on children's comprehension of relative clauses in Hebrew and Italian. Lingua. 122, 1053-69.

Booth, J., MacWhinney, B. \& Harasaki, Y. (2000). Developmental differences in visual and auditory processing of complex sentences. Child Development. 71, 981-1003.

Carpenter, P. A., Miyake, A. \& Just, M. A. (1994). Working memory constraints in comprehension: Evidence from individual differences, aphasia, and aging. In M. A. Gernsbacher (Ed.), Handbook of psycholinguistics (pp. 1075-1122). San Diego: Academic Press.

Chomsky, N. (1995). The Minimalist Program. Cambridge, MA: MIT Press.

Conway, A., Kane, M., Bunting, M., Hambrick, D., Wilhelm, O. \& Engle, R. (2005). Working memory span tasks: A methodological review and user's guide. Psychonomic Bulletin \& Review. 12, 769-786.

Cowan, N. (1995). Attention and Memory: An Integrated Framework. Oxford, England: Oxford University Press.

Cowan, N., Elliott, E., Saults, S., Morey, C., Mattox, S., Hismjatullina, A. \& Conway, A. (2005). On the capacity of attention: Its estimation and its role in working memory and cognitive aptitudes. Cognitive Psychology. 51, 51, 42-100.

Dick, F., Wulfeck, B., Krupa-Kwiatkowski, M. \& Bates, L. (2004). The development of complex sentence interpretation in typically developing children compared with children with specific language impairment or early unilateral focal lesions. Developmental Science. 7, 360-377.

Engle, R., Tuholski, S., Laughlin, J. \& Conway, A. (1999). Working memory, short-term memory and general fluid intelligence: A latent variable approach. Journal of Experimental Psychology: General. 128, 309-331.

Friedmann, N., Belletti, A. \& Rizzi, L. (2009). Relativized relatives: Types of intervention in the acquisition of A-bar dependencies. Lingua. 119, 67-88.

Friedman, N. \& Novogrodsky, R. (2004). The acquisition of relative clause comprehension in Hebrew: A study of SLI and normal development. Journal of Child Language. 31, 661681.

Fedorenko, E., Gibson, E. \& Rohde, D. (2006). The nature of working memory in sentence comprehension: Evidence against domain-specific working memory resources. Journal of Memory and Language. 54, 541-553.

Garnsey, S., Tanenhaus, M. \& Chapman, R. (1989). Evoked potentials and the study of sentence comprehension. Journal of Psycholinguistic Research. 18, 51-60.

Gibson, E. (1998). Linguistic complexity: Locality of syntactic dependencies. Cognition, 68, 1-76.

Gordon, P., Hendrick, R. \& Levine, W. (2002). Memory-load interference in syntactic processing. Psychological Science. 13, 425-430.

Gordon, P., Hendrick, R., \& Johnson, M. (2001). Memory interference during language processing. Journal of Experimental Psychology: Learning, Memory, and Cognition. 27, 1411-1423.

Gordon, P., Hendrick, R. \& Johnson, M. (2004). Effects of noun phrase type on sentence complexity. Journal of Memory and Language. 51, 97-114. 
Hassan, A. (2002). Tatabahasa Bahasa Melayu: Morfologi dan Sintaksis untuk Guru dan Pelajar. Kuala Lumpur: Akademia.

Halford, G. S., Wilson, W. H. \& Phillips, S. (1998). Processing capacity defined by relational complexity: Implications for comparative, developmental, and cognitive psychology. Behavioral and Brain Sciences. 21, 803-865.

Hestvik, A., Bradley, E. \& Bradley, C. (2012). Working memory effects of gap-predictions in normal adults: An event-related potentials study. Journal of Psycholinguistics. 41, 425438.

Hestvik, A., Maxfield, N., Schwartz, R. \& Shafter, V. (2007). Brain responses to filled gaps. Brain and Language. 100, 301-316.

Hornstein, N. \& Nunes, J. (2002). On asymmetries between parasitic gap and across-the-board constructions. Syntax. 5, 26-54.

Just, M. A. \& Carpenter, P. A. (1992). A capacity theory of comprehension: Individual differences in working memory. Psychological Review. 99, 122-149.

Just, M. A., Carpenter, P. A. \& Keller, T. A. (1996). The capacity theory of comprehension: New frontiers of evidence and arguments. Psychological Review, 103, 773-780.

Kane, M., Bleckley, M., Conway, A. \& Engle, R. (2001). A controlled-attention view of working memory capacity. Journal of Experimental Psychology: General. 130, 169183.

Karim, N. S., Onn, F. M., Musa, H. \& Mahmood, A. H. (1994). Tatabahasa Dewan. Kuala Lumpur: Dewan Bahasa dan Pustaka.

Kas, B. \& Lukas, A. (2012). Processing relative clauses by Hungarian typically developing children. Language and Cognitive Processes. 27, 500-538.

Kayne, R. S. (1994). The Antisymmetry of Syntax. Linguistic Inquiry Monograph 25. Cambridge, Massachusetts: MIT Press.

Kimball (1973). Seven principles of surface structure parsing in natural language. Cognition. $2,15-47$.

Kim, J. H. \& Christianson, K. (2013). Sentence complexity and working memory effects in ambiguity resolution. Journal of Psycholinguistic Research. 42, 393-411.

King, J. \& Just, M. (1991). Individual differences in syntactic processing: The role of working memory. Journal of Memory and Language. 51, 97-114.

Knowles, G. \& Zuraidah Mohd. Don. (2006). Word Class in Malay: A Corpus-Based Approach. Kuala Lumpur: Dewan Bahasa dan Pustaka.

Leech, R., Aydelott, J., Symons, G., Carnevale, J. \& Dick F. (2007). The development of sentence interpretation: Effects of perceptual, attentional, and semantic interference. Developmental Science. 10, 794-813.

Lewis, R. (1996). A theory of grammatical but unacceptable embeddings. Journal of Psycholinguistic Research. 25, 93-116.

Lewis, R., Vasishth, S. \& Van Dyke, J. (2006). Computational principles of working memory in sentence comprehension. Trends in Cognitive Sciences. 10, 447-545.

McElree, B. (2000). Sentence comprehension is mediated by content-addressable memory structures. Journal of Psycholinguistic Research. 29, 111-123.

McElree, B., Foraker, S. \& Dyer, L. (2003). Memory structures that sub-serve sentence comprehension. Journal of Memory and Language. 48, 67-91.

Mertus, J. A. (2000). The Brown Lab Interactive Speech System [Computer software]. Providence, RI: Brown University. Retrieved from http://mertus.org/Bliss/.

Meyers, L. S., Gamst, G. C. \& Guarino, A. J. (2013). Applied Multivariate Research: Design and Interpretation. California: Sage Publications.

Miller, G. \& Isard, S. (1964). Free recall of self-embedded English sentences. Information and Control. 7, 292-303. 
Miyake, A. \& Shah, P. (2007). Models of Working Memory: Mechanisms of Active Maintenance and Executive Control. New York: Cambridge University Press.

Mohamed Salleh, R. T. A., Kawaguchi, S. \& Di Biase, B. (2019). A case study on the acquisition of plurality in a bilingual Malay-English context-bound child. GEMA Online ${ }^{\circledR}$ Journal of Language Studies. 19, 22-42.

Nagaraj, N. (2014). Explaining Listening Comprehension in Noise using Auditory Working Memory, Attention and Speech Tests. PhD Dissertation. Department of Communication Sciences and Disorders, Ohio University, USA.

Pereltsvaig, A. (2012). Languages of the World: An Introduction. New York: Cambridge University Press.

Razak, R. A. (2014). Studies on the acquisition of morphology and syntax among Malay children in Malaysia: Issues, challenges and needs. In H. Winskel \& P. Padakannaya, (Ed) (2014). South and Southeast Asian Psycholinguistics (pp. 133-144). New York: Cambridge University Press.

Razak, R. A., Jin, L., Lim, H. W. \& Aziz, M. A. (2016). Profiling Malay children's syntactic development: A Malay-LARSP. In Fletcher, P., Ball, M. J. \& Crystal, D. (Ed) (2016). Profiling Grammar: More Languages of LARSP (pp. 135-169). Multilingual Matters/ Channel View Publications.

Riffle, T. \& DiGiovanni, J. (2013). Assessing Listening Effort in Hearing Impaired Individuals using Cognitive Tasks in Various Background Noise. Unpublished First-Year Project, Department of Communication Sciences and Disorders, Ohio University, USA.

Roberts, L., Marinis, T., Felser, C. \& Clahsen, H. (2007). Antecedent priming at trace positions in children's sentence processing. Journal of Psycholinguistic Research, 36, 175-188.

Rossion, B. \& Pourtois, G. (2004). Revisiting Snodgrass and Vanderwart's object set: The role of surface detail in basic-level object recognition. Perception. 33, 217-236

Salehuddin, K., Winskel, H. \& Maros, M. (2011). The pragmatic functions of numeral classifiers in modern Malay written corpus. GEMA Online ${ }^{\circledR}$ Journal of Language Studies. 11, 137-153.

Salehuddin, K. \& Winskel, H. (2012). Malay numeral classifier usage in caretaker-child talk. GEMA Online ${ }^{\circledR}$ Journal of Language Studies. 12, 89-104.

Schneider, W., Eschman, A., \& Zuccolotto, A. (2002). E-Prime User's Guide. Pittsburgh: Psychology Software Tools Inc.

Swets, B., Desmet, T., Hambrick, D. Z. \& Ferreira, F. (2007). The role of working memory in syntactic ambiguity resolution: A psychometric approach. Journal of Experimental Psychology: General. 136, 64-81.

Swinney, D., Zurif, E., Prather, P. \& Love, T. (1996). Neurological distribution of processing operations underlying language comprehension. Journal of Cognitive Neuroscience, 8 , 174-184.

Taube-Schiff, M. \& Segalowitz, N. (2005). Linguistic attention control: Attention shifting governed by grammaticized elements of language. Journal of Experimental Psychology: Learning, Memory and Cognition. 31, 508-519.

Unsworth, N. \& Engle, R. (2008). Speed and accuracy of accessing information in working memory: An individual differences investigation of focus switching. Journal of Experimental Psychology: Learning, Memory, and Cognition. 34, 616-630.

Van Dyke, J. (2007). Interference effects from grammatically unavailable constituents during sentence processing. Journal of Experimental Psychology: Learning. Memory and Cognition. 33, 407-430.

Van Dyke, J. \& Lewis, R. (2003). Distinguishing effects of structure and decay on attachment and repair: A cue-based parsing account of recovery from misanalysed ambiguities. Journal of Memory and Language. 49, 285-316. 
Van Dyke, J. \& McElree, B. (2006). Retrieval interference in sentence comprehension. Journal of Memory and Language. 55, 157-166.

Van Dyke, J. \& McElree, B. (2011). Cue-dependent interference in comprehension. Journal of Memory and Language. 65, 257-263.

Von Berger, E., Wulfeck, B., Bates, E. \& Fink, N. (1996). Developmental changes in real-time sentence processing. First Language. 16, 193-222.

Vos, S. H. \& Friederici, A. D. (2003). Intersentential syntactic context effects on comprehension: The role of working memory. Cognitive Brain Research. 16, 111-122.

Wee, L. H. A. (1996). Cognition in Grammar: The Problem of Verbal Prefixation in Malay. PhD Dissertation, Department of Linguistics, University of California-Berkeley, USA.

Winskel, H. \& Padakannaya, P. (2014). South and Southeast Asian Psycholinguistics. Cambridge: Cambridge University Press.

\section{ABOUT THE AUTHORS}

Yazmin Ahmad Rusli is currently the head of the Speech Sciences Program, Faculty of Health Sciences, UKM. Her research focuses on creating public awareness on developmental language disorders (DLD) and working on developing language and memory homespun tasks to identify and understand the mechanisms underlying difficulties in children with DLD.

James Montgomery is a professor and associate director; Division of Communication Sciences and Disorders, School of Rehabilitation and Communication Sciences, Ohio University. He is an expert on examining the intersection between memory and sentence comprehension in typically developing and children with DLD, and the development of memory-based models of sentence comprehension. 